\title{
The Importance of Museum Biomaterial Resources and Specimen Records for the Advancement of Zoological Research in Southern Africa
}

\author{
Zamawelase Mwelase ${ }^{\ddagger}$ \\ ‡ Durban Natural Science Museum, Durban, South Africa
}

Corresponding author: Zamawelase Mwelase (zama.mwelase@durban.gov.za)

Received: 02 May 2018 | Published: 04 Jul 2018

Citation: Mwelase Z (2018) The Importance of Museum Biomaterial Resources and Specimen Records for the Advancement of Zoological Research in Southern Africa. Biodiversity Information Science and Standards 2 : e26350. https://doi.org/10.3897/biss.2.26350

\begin{abstract}
The Durban Natural Science Museum (DNSM) Mammal Department was established in 1989. The Mammal Department is one of three zoological divisions and is the youngest and the most active collection within the institution. It is considered as one the fastest growing mammal collections in southern Africa and is comprised of 17,200 specimens belonging to ca. 450 species. The collection's primary focus is small mammals and small mammal research. The collection has amassed five holotypes and 31 paratypes - all of which represent Afrotropical small mammalian taxa described within the past decade. The department generates about 12 - 15 loans per annum, most of which represent biomaterial transfers (following international guidelines and standards).

Our collection material and specimen records support approximately 10 peer-reviewed publications on average per annum. The specimen material is accessed by local and international researchers and contributes towards various projects ranging from comparative morphological studies, taxonomic and systematic investigations, DNAsequence based studies and stable isotope analyses; to mention but a few. The departmental database has recently been migrated from Microsoft Access to Specify 7 software. This upgrade has greatly assisted curatorial and technical staff in managing access to collection material and specimen information, as it has streamlined the amount of
\end{abstract}


administration work associated with such tasks. Staff at the DNSM continue to strive to find innovative technologies and techniques to enable our collection material to be more accessible to a wider audience and to become an internationally-recognized authority on Afrotropical small mammalian biodiversity.

\section{Keywords}

biomaterial resources, specimen records, zoological research

\section{Presenting author}

Zamawelase Mwelase

\section{Presented at}

SPNHC-TDWG Joint Conference 2018

\section{Acknowledgements}

Dr Leigh Richards

\section{Funding program}

Natural Science Collections Facility (NSCF)

\section{Grant title}

“NSCF Travel Grant application”

\section{Hosting institution}

Otago Museum and the University of Otago, New Zealand

\section{Conflicts of interest}

None 